\title{
The influence of temperature and inlet velocity on cyclone pressure drop: a CFD study
}

\begin{abstract}
This work presents a computational fluid dynamics (CFD) calculation to predict and to evaluate the effects of temperature and inlet velocity on the pressure drop of gas cyclones. The numerical solutions were carried out using spreadsheet and commercial CFD code Fluent 6.1. This paper also reviews four empirical models for the prediction of cyclone pressure drop, namely [Air pollution control: a design approach, in: C. David Cooper, F.C. Alley (Eds.), Cyclones, second ed., Woveland Press Inc., Illinois, 1939, p. 127ï 139] [Chem. Eng. (1983) 99] [Doctoral Thesis, Havarad University, USA, 1988], and [Chem. Eng. Progress (1993) 51]. All the predictions proved to be satisfactory when compared with the presented experimental data. The CFD simulations predict excellently the cyclone pressure drop under different temperature and inlet velocity with a maximum deviation of $3 \%$ from the experimental data. Specifically, results obtained from the computer modelling exercise have demonstrated that CFD is a best method of modelling the cyclones operating pressure drop.
\end{abstract}

Keyword: Cyclone; CFD; Pressure drop; Temperature; Inlet velocity 